\title{
Aspectos sociodemográficos da soroprevalência de marcadores do vírus da hepatite A no povoado de Cavunge, região do semi-árido do Estado da Bahia
}

\author{
Sociodemographical aspects of seroprevalence of hepatitis A virus in the \\ settlement of Cavunge, a semi-arid region of Bahia State
}

\author{
Delvone Almeida ${ }^{1}$, José Tavares-Neto ${ }^{1}$, Marcony Queiroz-Andrade ${ }^{1}$, Camila Dias ${ }^{1}$, \\ Terezinha Ribeiro ${ }^{2}$, Francisco Silva ${ }^{2}$, Jailson Silva-Araújo ${ }^{1}$, Fernando Tatsch ${ }^{3}$ e Raymundo Paraná ${ }^{1}$
}

\section{RESUMO}

No Povoado de Cavunge, semi-árido da Bahia, foi realizado estudo sobre as hepatites com objetivo de avaliar a prevalência de portadores de IgG anti-VHA. Foram avaliados 891 moradores e 85,9\% foram soropositivos. A prevalência foi semelhante entre os sexos. Na zona urbana houve aumento da prevalência com a idade.

Palavras-chaves: Vírus da hepatite A. Epidemiologia. Marcadores sorológicos de hepatite. Cavunge. Bahia.

\begin{abstract}
In Cavunge community, a rural pvillage of the dry tropic in Bahia State, Brazil, a sentinel study on viral hepatitis was developed to characterize the seroprevalence of hepatitis A. The presence of IgG anti-HAV was analyzed in 891 citizens and $85.9 \%$ were positive. The prevalence was similar between genders and increased with age.
\end{abstract}

Key-words: hepatitis A virus. Epidemiology. Serological markers of hepatitis. Cavunge. Bahia.

A hepatite A costuma ser assintomática e apenas cerca de $20 \%$ dos casos desenvolve doença clinicamente manifesta, com graus variáveis de gravidade. Ocorre esporadicamente ou de forma epidêmica e a disseminação viral ocorre, sobretudo, em ambientes com precárias condições sociohigiênicas ${ }^{2}$.

A infecção é mais freqüente na infância, especialmente entre os menores de 5 anos de idade ${ }^{6}$. Em conseqüência disto e das características da transmissão do vírus da hepatite A (VHA), a melhoria dos indicadores de desenvolvimento humano tem grande impacto sobre a disseminação e transmissão viral ${ }^{7}$.

O diagnóstico laboratorial da infecção pelo VHA se faz na fase aguda, com a pesquisa dos anticorpos IgM anti-VHA, os quais tem títulos elevados até a $4^{\mathrm{a}}$ e a $6^{\mathrm{a}}$ semana pós-infecção e que desaparecem após o $4^{0}$ mês do início da mesma ${ }^{5}$. Os anticorpos neutralizantes $\operatorname{IgG}$, anti-VHA, têm títulos perceptíveis desde o início do processo infeccioso e que perduram por longo tempo, ou por toda a vida ${ }^{9}$. Por conta desta característica do anti-VHA IgG e pelas características associadas à transmissão do VHA, foi planejado o estudo de soroprevalência na população do Povoado de Cavunge (município de Ipecaetá, Estado da Bahia), onde também a investigação das condições sanitárias e ambientais permite avaliar possíveis inter-relações com aquela infecção viral.

\section{MATERIAL E MÉTODOS}

0 estudo seccional de base populacional foi realizado no ano de 2000. A população de referência é de 2.049 pessoas, com idades entre 7 dias e 95 anos. Aqueles que aceitaram participar do estudo assinaram o termo de consentimento

\footnotetext{
1. Faculdade de Medicina da Bahia da Universidade Federal da Bahia, Salvador, BA, Curso de Pós-graduação em Medicina e Saúde, Salvador, BA. 2. Hospital Aliança, Salvador, BA. 3. Laboratório Roche - Divisão de Hepatites e Divisão Diagnóstica, Salvador, BA.

Órgãos financiadores: CNPq, Laboratório Roche, Capes/Cofecub 404/02.

Endereço para correspondência: Prof. Raymundo Paraná. Av. Juracy Magalhães Jr, 2096, Sala 510, 41920-000 Salvador, BA, Brasil.

Telefax: $5571350-4651$

e-mail: unif@svn.com.br

Recebido para publicação em 5/4/2004

Aceito em 8/9/2005
} 
pós-informado e responderam ao questionário sóciodemográfico, desde que observados o critério de inclusão (residência fixa há mais de 6 meses no Povoado de Cavunge) e exclusão (portadores de doença psiquiátrica ou crônicodegenerativa associadas a incapacidade de compreender os objetivos do estudo, independente da idade e desde que não tivessem responsáveis legais).

Uma amostra de sangue venoso foi colhida e a equipe do projeto analisava as condições de moradia.

As amostras séricas de todos os moradores que participaram do estudo $(n=1.843)$ tiveram iguais chances de serem sorteadas para a pesquisa do anti-VHA ( $\operatorname{IgG})$, utilizando Kit comercial (Roche Diagnóstica). Para isto, foram sorteadas aproximadamente $50 \%$ dos espécimes séricos $(n=923)$.

As análises estatísticas foram realizadas com auxílio do software SPSS (Statistical Package for Social Science). As associações foram consideradas estatisticamente significantes se a probabilidade do erro a foi $\leq 0,05(\leq 5 \%)$.

\section{RESULTADOS}

Das 923 amostras séricas, sorteadas aleatoriamente, em $24(2,6 \%)$ havia hemólise e em $8(0,9 \%)$ a quantidade de plasma era insuficiente e foram excluídas do estudo.

Entre as 891 amostras séricas, 85,9\% $(\mathrm{n}=765)$ apresentaram sorologia anti-VHA (IgG) positiva (Tabela 1). As pessoas soropositivas foram mais freqüentes $(\mathrm{p}<0,01)$ entre as residentes $(87,4 \%)$ do Povoado do que na área rural $(79,7 \%)$. A distribuição de soropositivos foi semelhante $(p>0,47)$ entre as pessoas do sexo masculino $(86,7 \%)$ e feminino $(85,1 \%)$.

Tabela 1 - Análise da seroprevalência do vírus da hepatite A na população de Cavunge (Bahia)

\begin{tabular}{|c|c|c|c|}
\hline \multirow{3}{*}{ Variável } & \multicolumn{2}{|c|}{ Sorologia para VHA, (\%) } & \multirow{3}{*}{ Valor de $\mathrm{p}$} \\
\hline & positiva & negativa & \\
\hline & $765(85,9 \%)$ & $126(14,1 \%)$ & \\
\hline \multicolumn{4}{|l|}{ Sexo } \\
\hline masculino & $(86,7)$ & $(13,3)$ & \\
\hline feminino & $(85,1)$ & $(14,9)$ & $>0,47$ \\
\hline Área de Residência & & & $<0,01$ \\
\hline rural & 79,7 & 20,3 & \\
\hline urbana & 87,4 & 12,6 & \\
\hline Idade & & & $<0,01$ \\
\hline $0 \vdash \dashv 4$ & 15,9 & 84,1 & \\
\hline $5 \longmapsto-10$ & 60,8 & 39,2 & \\
\hline $11 \longmapsto-20$ & 86,0 & 14,0 & \\
\hline $21 \longmapsto-30$ & 95,5 & 4,5 & \\
\hline $31 \longmapsto-150$ & 97,5 & 2,5 & \\
\hline $51 \longmapsto \mid 70$ & 98,5 & 1,5 & \\
\hline$>70$ & 100,0 & 0,0 & \\
\hline Média de Idade $( \pm \mathrm{DP})$ & $39,69( \pm 22,05)$ & $10,12( \pm 11,12)$ & $<10^{-20}$ \\
\hline Vaso sanitário & & & $>0,72$ \\
\hline sim, dentro & 85,9 & 14,1 & \\
\hline sim, fora & 87,3 & 12,7 & \\
\hline não & 84,7 & 15,3 & \\
\hline
\end{tabular}

A soropositividade anti-VHA (IgG) aumentou proporcionalmente com a idade (Tabela 1 ), sendo a média de idade dos soropositivos $(39,69 \pm 22,05$ anos $)$ estatisticamente maior $\left(p<10^{-20}\right)$ que a dos soronegativos (10,12 \pm 11,12 anos).

Os 891 moradores com as amostras séricas estudadas residiam em 293 domicílios, mas apenas em 7 (2,4\%) residências todos os seus membros foram soronegativos; não obstante, esses 7 domicílios tinham 1 ou 2 membros. Em 83 $(28,3 \%)$ domicílios havia moradores com sorologia positiva e negativa e em 203 (69,3\%) todos foram soropositivos.

Na Tabela 1, foram descritas as proporções de pessoas soropositiva sem vaso sanitário no domicílio $(84,7 \%)$, fora de casa $(87,3 \%)$ ou dentro de casa $(85,9 \%)$ e que foram estatisticamente semelhantes $(p>0,72)$. Também, não houve associação da soropositividade com condições do domicílio $(p>0,15)$, se carente ou não.

\section{DISCUSSÃo}

A soroprevalência $(85,9 \%)$ de portadores de anticorpos contra o vírus da hepatite A na região estudada do semi-árido do Estado da Bahia foi semelhante à de outras regiões do País, onde as freqüências são também elevadas ${ }^{1}$, especialmente nas localidades com condições passíveis à transmissão do vírus como aquelas com precários índices de desenvolvimento social e econômico ${ }^{3}$.

O significativo aumento da soroprevalência após os cinco anos de idade, não só pode evidenciar maior exposição ao VHA, como também é nessa faixa etária que ocorrem maior número de contatos extradomiciliares. Nas localidades do semi-árido do Nordeste, especialmente os de menor porte, como Cavunge, a poluição ambiental é talvez o maior determinante de várias doenças de transmissão fecal-oral e decorrente de múltiplos fatores, tanto sanitários como culturais ${ }^{4}$.

A hipótese inicial era que na área rural, pela maior precariedade das condições sanitárias da populaçã $0^{8}$, fosse encontrada maior percentual maior de soropositivos. No entanto, a seropositividade foi maior entre os residentes na zona urbana do Povoado, mostrando que, apesar de dispor de melhores indicadores de desenvolvimento humano ${ }^{8}$, são ainda bastante precárias as condições sanitárias e ambientais naquela localidade. Por uma vez, a maior proximidade dos domicílios na zona urbana e o maior acúmulo das deficiências sanitárias, talvez sejam os mecanismos facilitadores da disseminação do VHA.

Cerca de $70 \%$ dos domicílios apresentaram todos os seus moradores com sorologia positiva para o VHA, o que sugere que a transmissão intradomiciliar é outro fator contribuidor na disseminação da infecção. Estes indicadores reforçam a necessidade do controle das infecções entéricas por meio de medidas relacionadas à melhoria nas condições de saneamento e de vida da população. Ao mesmo tempo, a grande extensão territorial do Brasil e a variabilidade sociodemográfica da sua população justificam mais estudos dessa natureza, com instrumento de informações úteis ao planejamento de estratégias de saúde coletiva, voltadas ao controle e a profilaxia das doenças de transmissão fecal-oral. 


\section{AGRADECIMENTOS}

A Roche Diagnóstica e ao Hospital Aliança.

\section{REFERÊNCIAS BIBLIOGRÁFICAS}

1. Clemens S, Fonseca J, Azevedo T, Cavalcanti A, Silveira T, Castilho M, Clemens R. Hepatitis A and hepatitis B seroprevalence in four centers in Brazil. Revista da Sociedade Brasileira de Medicina Tropical 33:1-10, 2000.

2. Franco E, Giambi C, Ialaci R, Coppola RC, Zanetti AR. Risk groups for hepatitis A virus infection. Vaccine 21: 2224-2233, 2003.

3. Poovorawan Y, Theambooniers A, Chumdermpadetsuk S. Changing seroepidemiology of hepatitis A virus infection in Thailand. Southeast Asian Jounal of Tropical Medicine and Public Health 24: 250-254, 1993.
4. Rosentahl P. Cost-effectiveness of hepatitis A vaccination in children, adolescents and adults. Hepatology 37: 44-51, 2003.

5. Sjogren M. Serologic diagnosis of viral hepatitis. Gastroenterologic Clinics of North America 23: 457-478, 1994.

6. Staes C, Schlenker T, Risk I, Cannon K, Harris H, Pavia A, Shapiro C, Bell B. Sources of infection among persons with acute hepatitis A and no identified risk factors during a sustained community-wide outbreak. Pediatrics 106: 54, 2000.

7. Tanaka J. Hepatitis A shifting epidemiology in Latin America. Vaccine 18 (supl I): S57-60, 2000.

8. Tavares-Neto J, Barral A, Queiroz-Andrade M, Oliveira S. Caracterização Sócio-demográfica da População do Povoado de Cavunge, Bahia. Revista Baiana de Saúde Pública 27: 60-75, 2003.

9. Vitral CL, Gaspar AMC, Yoshida CFT. Tow competitive enzyme immunoassays for the detection of IgG class antibodies to hepatitis A antigen. Revista da Sociedade Brasileira de Medicina Tropical 24:79-85, 1991. 